\title{
Raman spectroscopy of femtosecond laser written low propagation loss optical waveguides in Schott N-SF8 glass
}

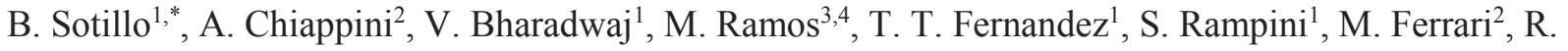 \\ Ramponi $^{1}$, P. Fernández ${ }^{5}$, B. Gholipour ${ }^{6}$, C. Soci ${ }^{3}$, S. M. Eaton ${ }^{1}$ \\ ${ }^{1}$ Istituto di Fotonica e Nanotecnologie-Consiglio Nazionale delle Ricerche (IFN-CNR) and Department of Physics, Politecnico di \\ Milano, Piazza Leonardo da Vinci 32, Milano, Italy \\ ${ }^{2}$ Institute of Photonics and Nanotechnology of the National Research Council (IFN-CNR), Characterization and Development of \\ Materials for Photonics and Optoelectronics (CSMFO) and The Centre for Materials and Microsystems (FBK-CMM), Trento, Italy \\ ${ }^{3}$ Centre for Disruptive Photonic Technologies, TPI, SPMS, Nanyang Technological University, Singapore 637371, Singapore \\ ${ }^{4}$ ICRM, Interdisciplinary Graduate School, Nanyang Technological University, Singapore 639798, Singapore \\ ${ }^{5}$ Department of Materials Physics, Physics Faculty, University Complutense of Madrid, Spain \\ ${ }^{6}$ Optoelectronics Research Centre and Centre for Photonic Metamaterials, University of Southampton, Southampton SO17 1BJ, \\ United Kingdom \\ *Corresponding author: bsotillo@gmail.com
}

\begin{abstract}
We have performed high repetition rate femtosecond laser bulk modification of $\mathrm{TiO}_{2}-\mathrm{SiO}_{2}$ based glass (Schott N-SF8 glass), leading to a decrease in the refractive index near the focal volume. From $\mu$ Raman and X-ray microanalysis we have associated the decrease in the refractive index to a volume expansion due to glass network modifications induced by the laser irradiation. By writing two lines close together we have been able to confine the optical mode and obtain propagation losses of $0.7 \mathrm{~dB} / \mathrm{cm}$ in the near infrared.
\end{abstract}

Keywords: Ultrafast lasers, Glass waveguides, Raman spectroscopy

\section{Introduction}

Femtosecond laser microfabrication is a widely used technique to form optical circuits [1-3], microfluidic channels [4] or periodical patterns on the surface [5] of a great variety of materials. In particular, femtosecond laser pulses focused below the surface of a transparent material produce a highly localized and permanent change of the refractive index, through a nonlinear multiphoton absorption at the focal volume $[6,7]$. Due to the nonlinear nature of femtosecond laser-material interaction, the process has very high repeatability, precision and can be realized in any transparent dielectric.

Investigating the structural and compositional changes induced by the femtosecond laser in the material that lead to the change in the refractive index helps to understand the responsible physical process and thus improving the technique and the outcome. Various mechanisms have been proposed/observed to produce the increase in the refractive index in glasses: i) densification of the melted glass by rapid cooling [8, 9]; ii) formation of color centers [10] or iii) ion-migration in multicomponent glasses [11-13]. There are also a few examples in which the laser interaction produces a decrease in refractive index of the glass (i.e. phosphate glasses), where the decrease is associated to an overall expansion of the glass network [14, 15]. The appearance of these processes will depend on the composition of the glass. In the case of crystals the disruption of the ordered lattice produces a decrease in the refractive index [16-18].

$\mathrm{TiO}_{2}$ addition to the silica glass network is commonly used to tailor the optical, mechanical or thermal properties of the glass. Two main changes have been observed to occur with the addition of titanium to a 
silica matrix, both attractive from the spectroscopic point of view: the increase in the refractive index of the material [19-21] and the lowering of phonon energy. The former property is ideal for producing nonlinear optical devices [22, 23] whereas the latter is spectroscopically ideal for producing larger bandwidth and longer wavelength operating lasers and devices [24, 25]. $\mathrm{TiO}_{2}$-containing glasses have been also used for the development of optical fibers [26, 27]. The low Abbe number [19] at relatively high refractive index make Ti-containing glasses good substitutes for Pb-containing glasses for the fabrication of glassware or glass jewelry, being titanium less contaminating. Finally, titania-silicate glasses, with a few percent of $\mathrm{TiO}_{2}$, fabricated by a flame hydrolysis process are used in applications where very low thermal expansion $\left(\sim 10^{-8}-10^{-9} \mathrm{~K}^{-1}\right)$ is required (i.e. astronomical telescopes, space satellite applications, highprecision optics...) $[28,29]$.

In this paper we report the fabrication of low-loss type II waveguides in N-SF8 glass (titanium sodium silicate based glass) by high repetition rate femtosecond laser. N-SF8 glass is of great interest due to its use as the cladding material in GLS chalcogenide fibers, for applications in nonlinear photonics [30] We pay special attention to the changes produced in the structure of the glass, in order to understand the relationship between the observed material changes and the waveguiding behavior. We identify the mechanisms responsible for the femtosecond laser-induced morphology in N-SF8, allowing us to tailor the interaction to obtain low loss waveguides.

\section{Materials and methods}

The samples used in this work were $5 \mathrm{~cm} \times 5 \mathrm{~cm} \times 1 \mathrm{~mm} \mathrm{~N}$-SF8 glass acquired from Schott AG. The main raw oxide components of this glass, as indicated in the datasheet provided by the company [31], are: $\mathrm{SiO}_{2}\left(40-50\right.$ wt.\%), $\mathrm{TiO}_{2}\left(20-30\right.$ wt.\%) and $\mathrm{Na}_{2} \mathrm{O}(10-20$ wt.\%). Smaller quantities of the follow oxide compounds are also present, in a proportion of $1-10$ wt.\%: $\mathrm{B}_{2} \mathrm{O}_{3}, \mathrm{BaO}, \mathrm{CaO}, \mathrm{K}_{2} \mathrm{O}, \mathrm{Nb}_{2} \mathrm{O}_{3}, \mathrm{ZrO}_{2}$. The presence of all these elements is confirmed by energy dispersive X-ray microanalysis (EDX, Fig. 1). The average composition of the glass, according to the EDX measurements, is: $35 \mathrm{wt} . \%$ of $\mathrm{SiO}_{2}, 20$ wt. $\%$ of $\mathrm{TiO}_{2}, 8$ wt. $\%$ of $\mathrm{Na}_{2} \mathrm{O}, 7$ wt. $\%$ of $\mathrm{K}_{2} \mathrm{O}, 7$ wt. $\%$ of $\mathrm{BaO}, 2$ wt. $\%$ of $\mathrm{CaO}, 9$ wt. $\%$ of $\mathrm{B}_{2} \mathrm{O}_{3}, 8$ wt. $\%$ of $\mathrm{Nb}_{2} \mathrm{O}_{5}$ and $3 \mathrm{wt} . \%$ of $\mathrm{ZrO}_{2}$, similar to the values provided by the manufacturer, confirming that the main oxide components of the glass are $\mathrm{SiO}_{2}$ and $\mathrm{TiO}_{2}$ with alkali oxides and alkaline earth oxides as network modifiers. Some of the physical properties of N-SF8 glass are listed in Table 1.

\begin{tabular}{|c|c|c|}
\cline { 2 - 3 } \multicolumn{2}{c|}{} & Schott AG N-SF8 properties \\
\hline \multicolumn{2}{|c|}{ Density } & $2.9 \mathrm{~g} / \mathrm{cm}^{3}$ \\
\hline \multicolumn{2}{|c|}{ Refractive index @ 546 nm } & 1.69 \\
\hline \multicolumn{2}{|c|}{ Transmittance range } & $390-2325 \mathrm{~nm}$ \\
\hline $\begin{array}{l}\text { Coefficient of } \\
\text { expansion }\end{array}$ & $-30 /+70^{\circ} \mathrm{C}$ & $8.6 \times 10^{-6} \mathrm{~K}^{-1}$ \\
\cline { 2 - 3 } & $+20 /+300^{\circ} \mathrm{C}$ & $9.9 \times 10^{-6} \mathrm{~K}^{-1}$ \\
\hline \multicolumn{2}{|c|}{ Thermal conductivity } & $1.03 \mathrm{~W} /\left(\mathrm{m}^{\circ} \cdot \mathrm{K}\right)$ \\
\hline \multicolumn{2}{|c|}{$\mathbf{T}_{\mathbf{g}}$} & $567^{\circ} \mathrm{C}$ \\
\hline
\end{tabular}

Table 1. Physical properties of N-SF8 glass [32]. 


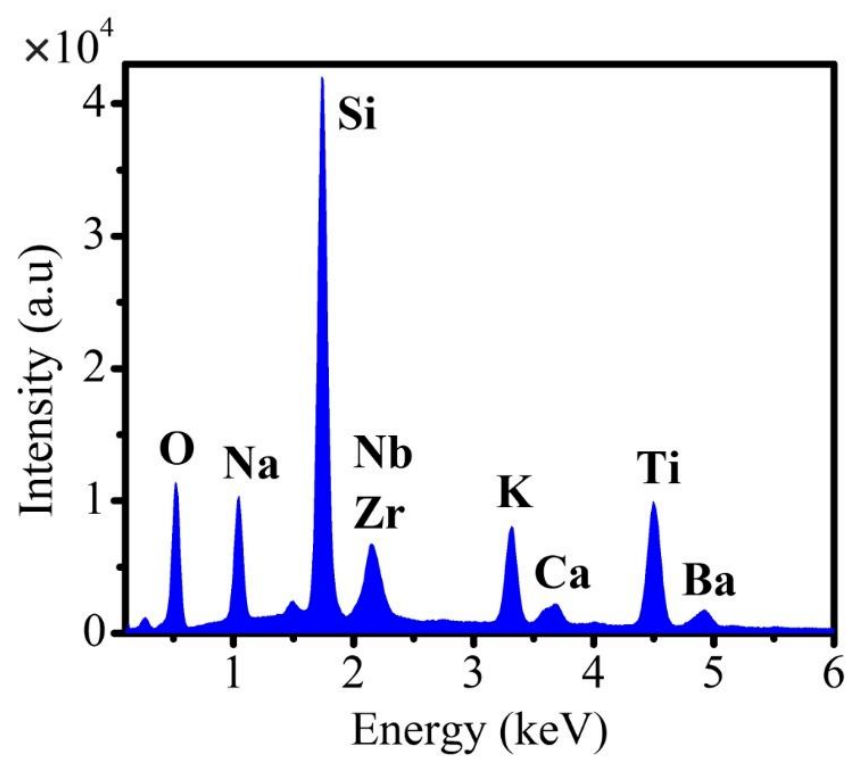

Fig. 1. Typical EDX spectrum measured on the pristine glass, showing the elements detected.

A regeneratively amplified Yb:KGW system (Pharos, Light Conversion) with a pulse duration of 230 fs was used for the fabrication of waveguides in N-SF8 glass. The wavelength employed in the writing was $515 \mathrm{~nm}$, with the polarization perpendicular to the scan direction. The repetition rate was $500 \mathrm{kHz}$. A high NA oil immersion lens (1.25 NA, RMS100X-O $100 \times$ Olympus Plan Achromat Oil Immersion Objective) was used to reduce the detrimental effects of self-focusing [33] and spherical aberration [34]. Computer-controlled, 3-axis motion stages (ABL-1000, Aerotech) interfaced by CAD-based software (ScaBase, Altechna) with an integrated acousto-optic modulator (AOM) were used to translate the sample relative to the laser to form the desired photonic structures. All the waveguides have been formed at a depth of $110 \mu \mathrm{m}$ below the surface.

Laser-inscribed structures were characterized for their morphology using white-light optical microscopy in transmission mode with $10 \times$ and $40 \times$ magnification objectives (Eclipse ME600, Nikon). For waveguide transmission measurements, high resolution 3 -axis manual positioners (Nanomax MAX313D, Thorlabs) were used. The four-axis central waveguide manipulator (MicroBlock MBT401D, Thorlabs) enabled transverse displacement between sets of waveguides. Light source at $808 \mathrm{~nm}$ (S1FC808, Thorlabs) was used to test the waveguides, and the light was coupled to the waveguides using Thorlabs single-mode fibers $780 \mathrm{HP}$ (Mode Field Diameter of $5.5 \pm 0.5 \mu \mathrm{m}$ at $850 \mathrm{~nm}$ wavelength). To measure the near-field waveguide mode profile, a $60 \times$ asphere (5721-H-B, Newport) was used to image the light to a beam profiler (SP620U, Spiricon).

$\mu$ Raman spectra were recorded using a Labram Aramis Jobin Yvon Horiba $\mu$ Raman system with a DPSS laser source of $532 \mathrm{~nm}$ and equipped with a confocal microscope and an air-cooled CCD. A 100× objective was used to focus the laser on the sample as well as to collect the Raman spectra, with a spatial resolution of about 1 micron. A wavenumber accuracy of about $1 \mathrm{~cm}^{-1}$ can be achieved with a 1800 line/mm grating.

Energy dispersion X-ray microanalysis (EDX) has been performed in a Bruker Quantax 70 EDS system attached to a scanning electron microscope Hitachi TM3000, operated at $15 \mathrm{kV}$. The energy resolution for this system is around $154 \mathrm{eV}$ (for $\mathrm{Cu} \mathrm{K \alpha}$ ). 
Published in Optical Materials 72, pp. 626-631 (2017).

https://authors.elsevier.com/a/1VMOu3IPalOGPb

\section{Results and discussion}

\subsection{Bulk modification in the glass induced by the femtosecond laser}

The processing parameters that were used for the study on the N-SF8 glass were an average power of $50-400 \mathrm{~mW}$, a scan speed of $2-50 \mathrm{~mm} / \mathrm{s}$ and a repetition rate of $500 \mathrm{kHz}$. We have observed that for writing powers of $400 \mathrm{~mW}$ or higher the modification lines had micro-cracks around them, which are undesirable for photonic applications.

Fig. 2a shows the images from the white light transmission optical microscopy of the longitudinal and transverse view of some of the structures written. The dark regions in the structures are attributed to lower refractive index regions due to the absence of light guiding. To ensure that there are no shadows cast into the region of interest resulting in ambiguous results, we have used Köhler illumination technique to specifically and uniformly illuminate the area of interest. As can be seen in Fig. 2a, the transverse width increased considerably with an increase in average power or a decrease in scan speed. This indicates a good three-dimensional heat flow during the waveguide inscription owing to the moderately high thermal conductivity of the N-SF8 glass $(1.03 \mathrm{~W} / \mathrm{m} \cdot \mathrm{K})$ that is comparable to other silicate glasses like BK7 $(1.11 \mathrm{~W} / \mathrm{m} \cdot \mathrm{K})$ and Corning Eagle $2000(1.09 \mathrm{~W} / \mathrm{m} \cdot \mathrm{K})[35,36]$.

\section{(a)}

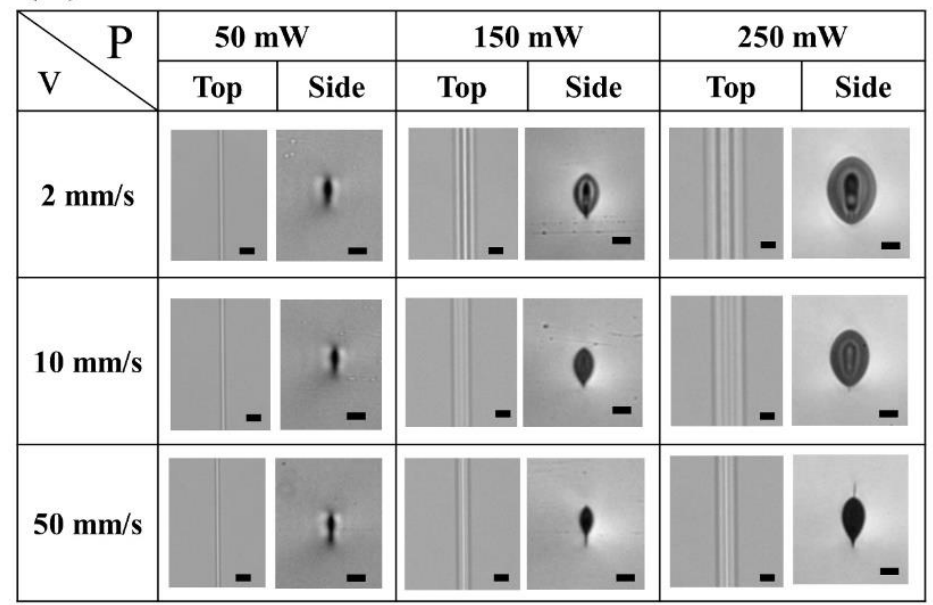

(b)

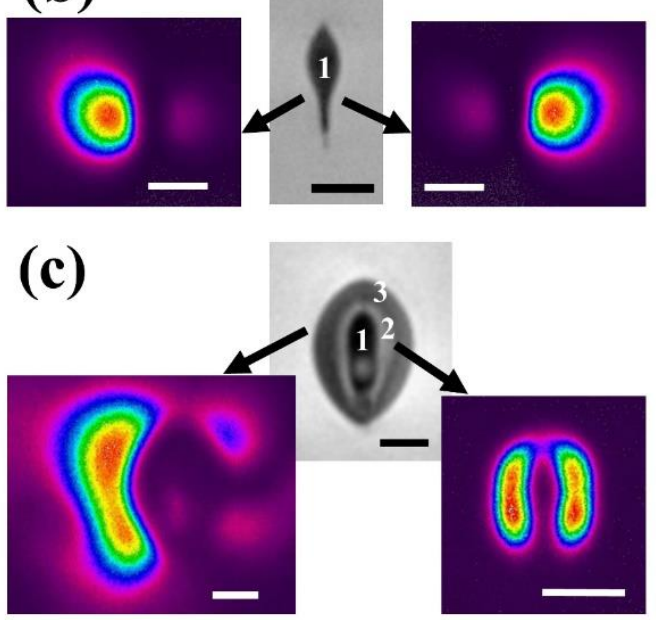

Fig. 2. (a) Transmission optical microscope images (side and top views) of the laser-written structures obtained for different average powers $(P)$ and writing velocities $(v)$. (b) Near-field intensity mode profiles (wavelength of $808 \mathrm{~nm}$ ) measured for a structure formed with $50 \mathrm{~mW}$ and $50 \mathrm{~mm} / \mathrm{s}$, showing that the light can be guided on both sides of the dark central region. (c) Near-field intensity mode profiles (wavelength of $808 \mathrm{~nm}$ ) measured when light is coupled inside and outside a slightly larger structure written with higher net fluence $(200 \mathrm{~mW}$ and $2 \mathrm{~mm} / \mathrm{s})$. All the scale bars are $10 \mu \mathrm{m}$. In the mode profile images, note the color linear scale varying from 0 (violet) to 1 (red) indicates the relative intensity of the mode profile, normalized to the peak intensity.

For all the structures fabricated in N-SF8, it was not possible to guide light in the dark central region 1. The near-field intensity mode profiles at $808-\mathrm{nm}$ wavelength for two different structures are shown Fig. $2 \mathrm{~b}, \mathrm{c}$. For the structure formed with $50 \mathrm{~mW}$ and $50 \mathrm{~mm} / \mathrm{s}$ (Fig. 2b), it was possible to couple light on either side of the depressed refractive index region, by lateral translation of the input fiber. 
A closer inspection of the structures with larger diameter shows that the refractive index profile is not uniform. The white light transmission optical microscopy images (Fig. 2a) are similar to those reported in other glasses $[35,37,38]$, but in the case of N-SF8, the change in refractive index is the opposite. When observing the side view of the structure formed with $250 \mathrm{~mW}$ power and $2 \mathrm{~mm} / \mathrm{s}$ scan speed, three different regions can be distinguished: 1) a central elliptical region with a strong decrease in the refractive index, indicated by a darker color compared to the pristine glass, 2) an annular region (light grey) having a slightly higher refractive index compared to the central region it surrounds, 3 ) an outer cladding region (dark grey) with a refractive index greater than region 2, but lower refractive index than the bulk.

For a structure formed with higher net fluence $(200 \mathrm{~mW}$ and $2 \mathrm{~mm} / \mathrm{s})$, it is possible to couple light to both region 2 surrounding the central core, and also on either side of the structure (Fig. 2c), again by simply translating the input fiber laterally.

Waveguiding on either side of the modified region has been previously observed in crystals such as lithium niobate [17] and KGW [39] as well as in some glasses [14, 15]. For these materials, the structural changes produced by the laser irradiation induces a volume increase that compresses the surrounding regions which enables waveguiding. Therefore the fact that we see waveguiding outside of the modification zone in N-SF8 is likely related to the volume change/stress induced by the laser irradiation. Furthermore, the micro-cracks observed around the lines for higher powers point to the creation of stresses in the glass.

\subsection{Structural characterization of the laser-written lines}

To understand the laser-induced structural changes observed in the N-SF8 glass, first it is necessary to have an overview of the kind of network that can be found in titanium silicate glasses. As many previous works have pointed out [21, 40-45], the glass properties depend on the concentration of $\mathrm{TiO}_{2}$ as well as on the composition (binary system $\mathrm{TiO}_{2}-\mathrm{SiO}_{2}$ or multicomponent system, see for example [44] and references within). These works also reported different coordination number for Ti cations depending on the Ti concentration and glass composition. Looking at the oxides contained in the N-SF8 glass (see experimental methods section), it is mainly a titanium alkali/alkaline earth silicate glass. For titanium alkali and alkaline earth silicate glasses, it is suggested that for low concentrations of $\mathrm{TiO}_{2}$, titanium is incorporated with a coordination number of 4, forming 4 bonds with oxygen atoms in the same configuration as $\mathrm{Si}$ cations (tetrahedra). As $\mathrm{Ti}$ concentration increases, the coordination number increases also from ${ }^{[4]} \mathrm{Ti}$ to ${ }^{[5]} \mathrm{Ti}$, being coordination number of 5 dominant for high concentrations of $\mathrm{Ti}$ (above $10-15$ wt. $\%$ of $\mathrm{TiO}_{2}$ ) $[40,44,46]$.

Farges et al. [40], propose a model for the glass structure of sodium silicate glasses containing high concentration of $\mathrm{Ti}$, which they called the "percolation model". In this model, $\mathrm{Ti}^{4+}$ cations are incorporated forming square pyramids with 4 single bonds with 4 oxygen atoms and a double bond with a fourth oxygen, the titanyl oxygen $\left(\left({ }^{[5]} \mathrm{Ti}=\mathrm{O}\right) \mathrm{O}_{4}\right)$. These pyramids aggregate in clusters and, due to charge compensation, they attract the $\mathrm{Na}$ ions from the network, forming localized regions with high concentration of $\mathrm{Ti}$ and $\mathrm{Na}$. The addition of $\mathrm{TiO}_{2}$ promotes further formation of these clusters, meaning that there will be less $\mathrm{Na}$ around $\mathrm{Si}$, reducing the non-bridging oxygen population in the silica matrix. Then, the increase in density and refractive index observed under the incorporation of $\mathrm{TiO}_{2}$ to the glass can be associated to the mass difference of $\mathrm{Ti}$ and $\mathrm{Si}$ ions $\left(m_{\mathrm{Ti}} / m_{\mathrm{Si}}=1.71\right)$ as well as to the network constraint due to the presence of these clusters with higher local concentration of $\mathrm{Ti}$ and $\mathrm{Na}$ (percolation domains). This model of Ti-rich regions in the network of the glass was also confirmed later in $\mathrm{Ti}$ bearing potassium silicate glasses [47]. In N-SF8 glass, there are several network modifiers $\left(\mathrm{Na}^{+}, \mathrm{K}+\right.$, $\mathrm{Ba}^{2+}, \mathrm{Ca}^{2+} \ldots$ ), so we extend this model visualizing the glass as having Ti-rich regions or percolation domains with a higher concentration of network modifiers than in the silica network. 
The percolation model or Ti-rich regions in the glass has been successfully applied to explain some of the properties change of titanium alkali silicate glasses with temperature [41, 48, 49], or with composition [21].

$\mu$ Raman measurements and X-ray microanalysis have been performed to understand the structural and compositional changes induced by the laser in the glass. The typical Raman spectrum for the pristine N-SF8 glass is shown in Fig. 3a. It is composed of the following bands (from low to high frequency): band 1 between $200-400 \mathrm{~cm}^{-1}$, centered at $290 \mathrm{~cm}^{-1}$; band 2 between $400-600 \mathrm{~cm}^{-1}$, centered at 535 $\mathrm{cm}^{-1}$; broad band 3 between 650 and $1000 \mathrm{~cm}^{-1}$, where the component at $890 \mathrm{~cm}^{-1}$ is visible (band 4); and a band between $950-1100 \mathrm{~cm}^{-1}$ (band 5).
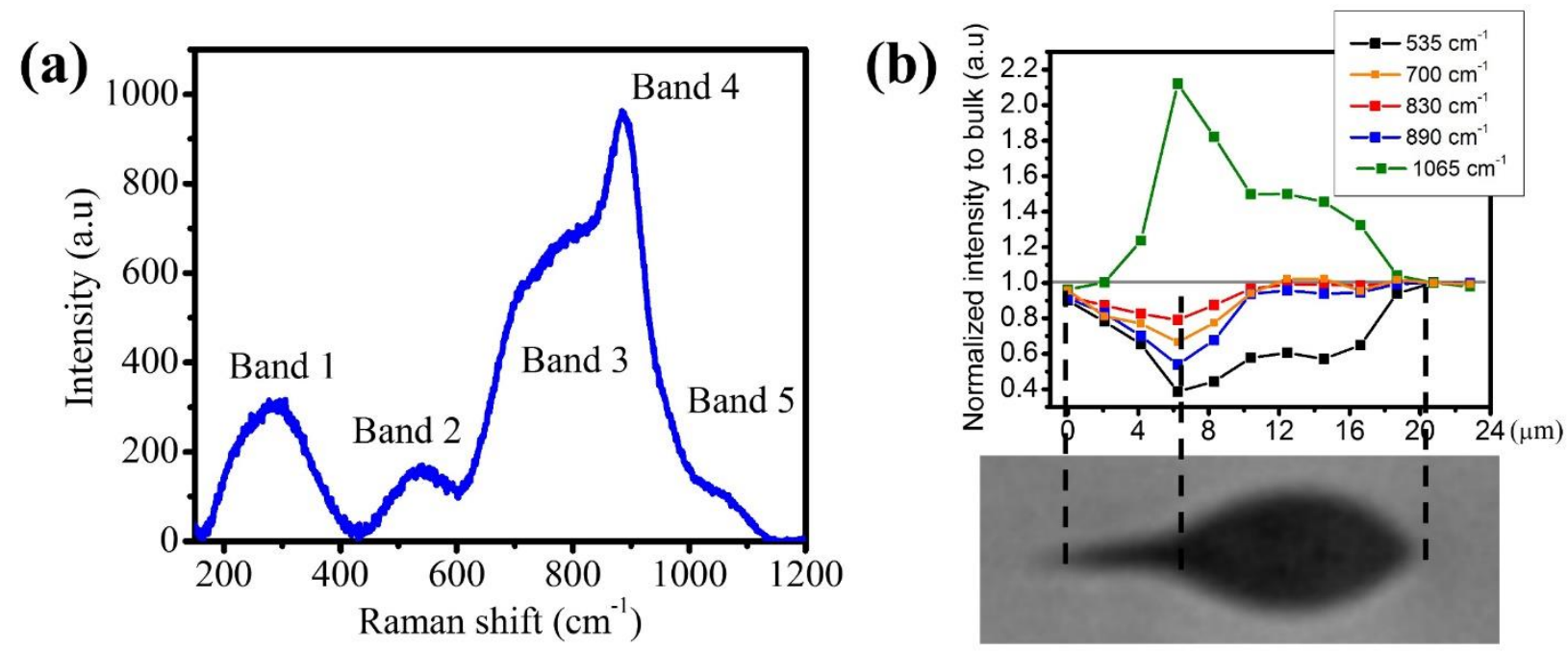

Fig. 3. (a) Raman spectrum measured on the pristine N-SF8 glass using $532 \mathrm{~nm}$ laser as excitation. The assignment for the main bands observed is also indicated. (b) Variation of the relative intensity of the Raman bands inside the laser-modified region $(100 \mathrm{~mW}, 20 \mathrm{~mm} / \mathrm{s})$ with respect to the pristine glass. Each band is labeled with the wavenumber at its center. The increase in intensity at $1065 \mathrm{~cm}^{-1}$ is associated to an increase of non-bridging oxygens in the silica network, whereas the decrease in intensity of the other bands is due to breakdown and disorder of the units responsible of the vibrations.

Band 1 has been rarely reported in the literature, but it could be associated to Ti related vibrations [21]. Band 2 is associated in alkali/alkaline earth silicate glasses to bending modes of the Si-O-Si linkages $[43,50]$. The broad band 3 is expected to have several components associated with the silicon network as well as with the titanium network. In this frequency region it has been reported the $\mathrm{Si}$ and $\mathrm{Ti}$ in their tetrahedral cage (at 800 and $720 \mathrm{~cm}^{-1}$ [21], respectively) and the vibrations of the Si-O-Ti linkages (reported at $840 \mathrm{~cm}^{-1}$ [51] for multicomponent system, as well as at around $950 \mathrm{~cm}^{-1}[52,53]$ for $\mathrm{TiO}_{2}$ $\mathrm{SiO}_{2}$ binary system). Band 5 is related to $\mathrm{Si}^{-} \mathrm{O}^{-}$non-bridging oxygen vibrations $\left(\mathrm{Q}^{2}\right.$ and $\mathrm{Q}^{3}$ units, being $\mathrm{Q}^{i}$ the silicon tetrahedral and $i$ the number of bridging oxygens) [43,50].

The well-defined band centered at $890 \mathrm{~cm}^{-1}$ has been typically observed in Ti-bearing alkali and alkaline earth silicate glasses, showing an increase in its intensity with the addition of more $\mathrm{TiO}_{2}$ [43]. In studies done in Ti-containing glasses with high concentration of titanium, it has been associated with vibrations of the $\mathrm{Ti}=\mathrm{O}$ double bond $[21,43,49]$. Expected values for the titanyl $\mathrm{Ti}=\mathrm{O}$ vibrations are in the range of $850-910 \mathrm{~cm}^{-1},[41,42,49]$, in good agreement with the position observed for our band 4 . 
Once the overview of the Raman bands of pristine N-SF8 glass is done, we now discuss the changes observed in the spectra from the laser-written structures. The first effect observed is that the total Raman intensity decreases inside the modification, suggesting the breaking of bonds and the creation of defects. No crystallization is produced by the irradiation of the glass with the laser [54], which can increase the losses of the waveguide [55]. The change in relative intensity compared to the pristine material of each component is plotted in Fig. 3b. Almost all the components show a decrease in the relative intensity inside the damaged region except the one corresponding to the band at $1065 \mathrm{~cm}^{-1}$. The band at $535 \mathrm{~cm}^{-}$ ${ }^{1}$ follows the opposite behavior of the band at $1065 \mathrm{~cm}^{-1}$. Bands centered at $250 \mathrm{~cm}^{-1}, 700 \mathrm{~cm}^{-1}, 830$ and $890 \mathrm{~cm}^{-1}$ show mainly a decrease in intensity at the lower tip of the tear-shape structure. Fig. 4 shows a two-dimensional map of the Raman intensity for the bands at 535, 890 and $1065 \mathrm{~cm}^{-1}$ within modifications written with: a) $100 \mathrm{~mW}, 20 \mathrm{~mm} / \mathrm{s}$ and b) $300 \mathrm{~mW}, 2 \mathrm{~mm} / \mathrm{s}$. The $890 \mathrm{~cm}^{-1}$ band is related to the formation of the ${ }^{[5]} \mathrm{Ti}$ square pyramids, whereas changes in $535 \mathrm{~cm}^{-1}\left(1065 \mathrm{~cm}^{-1}\right)$ is due to the decrease (increase) of the non-bridging oxygen in the silica matrix [21].

Changes observed in the Raman spectra could be related to laser-induced alteration of the structure and composition of N-SF8, as has been observed in other glasses [11, 12]. To gain further insight into the laser-induced compositional changes in N-SF8, EDX measurements were performed. Over the range of laser processing conditions tested $(50-400 \mathrm{~mW}$ power, $2-50 \mathrm{~mm} / \mathrm{s}$ speed), we did not observe Zcontrast in the SEM, which suggests that the laser irradiation did not induce a strong ion migration in the irradiated glass network. If there were ion migration, it could be easily observed in the backscatterelectron SEM images due to higher atomic mass $(Z)$ of titanium or the network modifiers compared to silicon. From the EDX measurements, no significant changes in the composition were observed and therefore we associate the decrease in the refractive index within the laser-modified structures to a network expansion, an effect also proposed for phosphate glasses [15], having a coefficient of thermal expansion $\left(11 \times 10^{-6} \mathrm{~K}^{-1}\right.$ for Schott IOG-1 phosphate glass) close to the value of the N-SF8 glass (see table $1)$.

Heat accumulation at $500-\mathrm{kHz}$ repetition rate results in high temperatures within the focal volume [36], which leads to a network expansion, confirmed in studies done in titanium alkali-silicate glasses and melts (above $T_{g}$ ), where a density decrease and an increase in volume is observed with increasing temperature [48]. Following the percolation model, the increase of the temperature produces the breakdown of the percolation domains, producing a less constrained glass network with more nonbridging oxygen as the modifier cations are dispersed more homogeneously in the melt structure [41, 48]. The quenching of this high temperature structure by the rapid cooling of the melted glass, not allowing the re-formation of the percolation domains, will produce the changes that we are observing in our laser-writing structures, i.e., the fast quenching of the melted glass results in an increase in the fictive temperature respect to the pristine material, which for N-SF8 corresponds to an expanded network with lower refractive index.

We propose the following explanation for the changes observed in the Raman spectra in N-SF8 after high repetition rate femtosecond laser irradiation. In the structures written with lower net fluence (Fig. 4a), three regions can be distinguished. In region I, at the top part of the black region, we observe small changes in the Raman spectra (Fig. 5), with a reduction of the intensity at $535 \mathrm{~cm}^{-1}$ and an increase in intensity at $1065 \mathrm{~cm}^{-1}$, and a slight intensity decrease of the $890 \mathrm{~cm}^{-1}$ band. In region II, located in the lower part of the structure, we obtain the largest changes in the Raman spectra (Fig. 5). As in region I, we observe a reduction of the intensity of 535 and $890 \mathrm{~cm}^{-1}$ bands and an increase of the $1065 \mathrm{~cm}^{-1}$ intensity. For both regions, this is associated with a breakdown of percolation domains (decrease in intensity of $890 \mathrm{~cm}^{-1}$ band) that release the network modifiers, producing an increase of non-bridging oxygens (increase in intensity at $1065 \mathrm{~cm}^{-1}$ ) in the silica network and more disorder in the Si-O-Si angles (decrease in intensity of $535 \mathrm{~cm}^{-1}$ band). This increase in disorder is also supported by the decrease in intensity of the bands related to $\mathrm{Si}$ and $\mathrm{Ti}$ vibrations in an oxygen cage $\left(700-800 \mathrm{~cm}^{-1}\right)$. Larger changes 
in the Raman spectra will indicate a bigger change in the glass structure in this region II, i.e. the increase in volume in region II is larger than in region I. It is in region III, located around region II, where we have observed the appearance of guiding regions, and it is formed by the compressive stress generated when region II expands due to the structural changes of the glass.

(a)

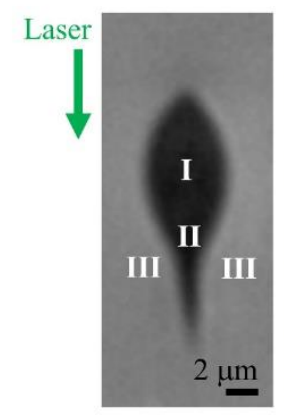

(b)

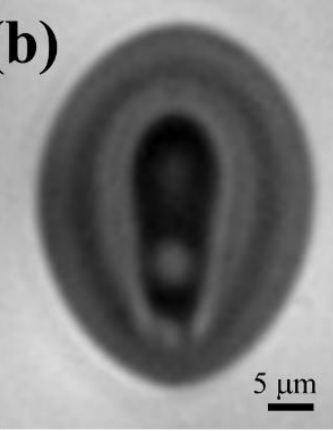

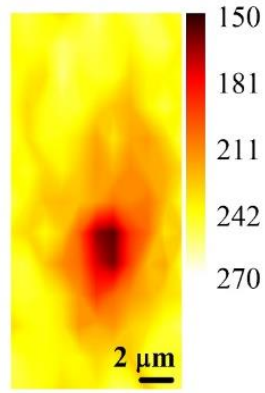

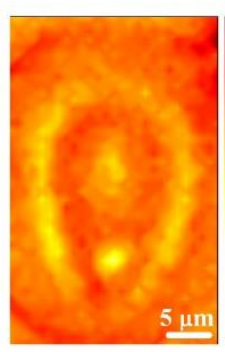

Integrated intensity
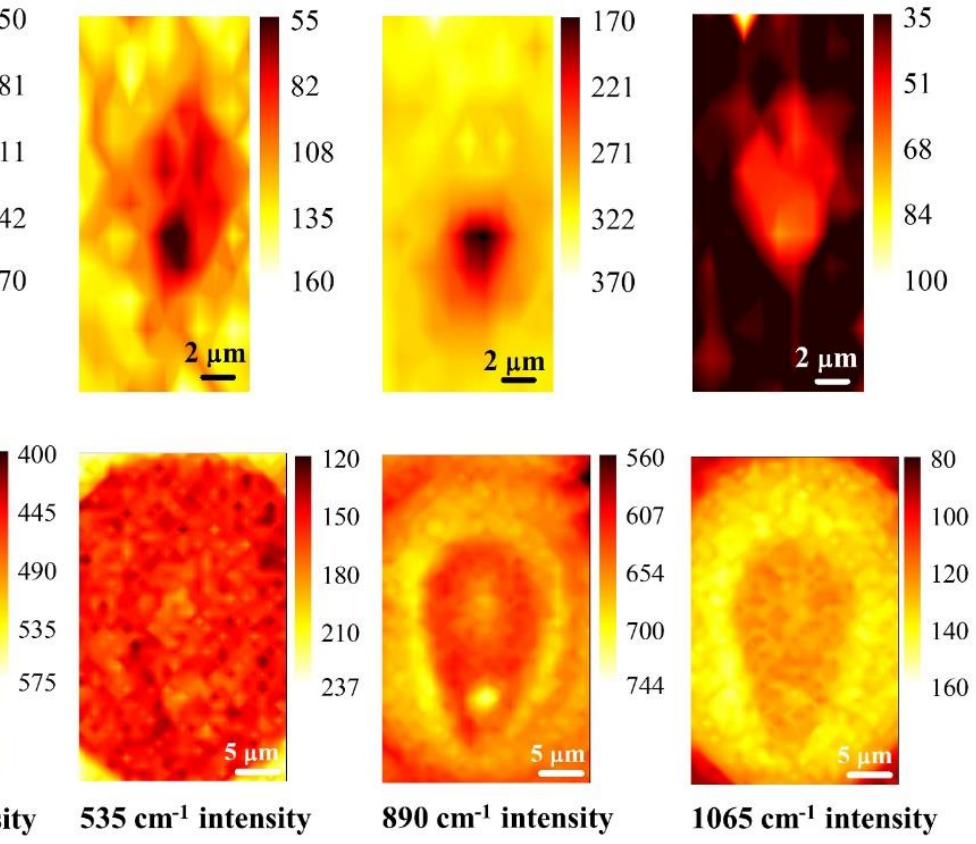

Fig. 4. Typical $\mu$ Raman intensity maps performed on laser-written lines inscribed with (a) lower net fluence $(100 \mathrm{~mW}, 20 \mathrm{~mm} / \mathrm{s})$; (b) higher net fluence $(300 \mathrm{~mW}, 2 \mathrm{~mm} / \mathrm{s})$. Along with the optical microscope images (left), it is shown the integrated intensity and the intensity of the 535, 890 and 1065 $\mathrm{cm}^{-1}$ bands (from left to right) for both structures. The intensity is expressed in a.u.

The Raman changes observed in the structures written with higher net fluence (Fig. 4b) are more complex. At the center of the structure, higher expansion of the network is produced (higher decrease of refractive index). Around it, a region with less pronounced Raman changes can be found, similar to region 1 in Fig. 4b. At the regions where we have been able to see lightguiding (annular region, indicated with 2 in Fig. 2c), the $890 \mathrm{~cm}^{-1}$ band associated with the ${ }^{[5]} \mathrm{Ti}$ pyramids' population has higher intensity, i.e. the refractive index is higher than in the surrounding material. Also, the stress induced around it by the central expanded glass can be contributing to the increased refractive index in the arc-like structure and in the central small core. 


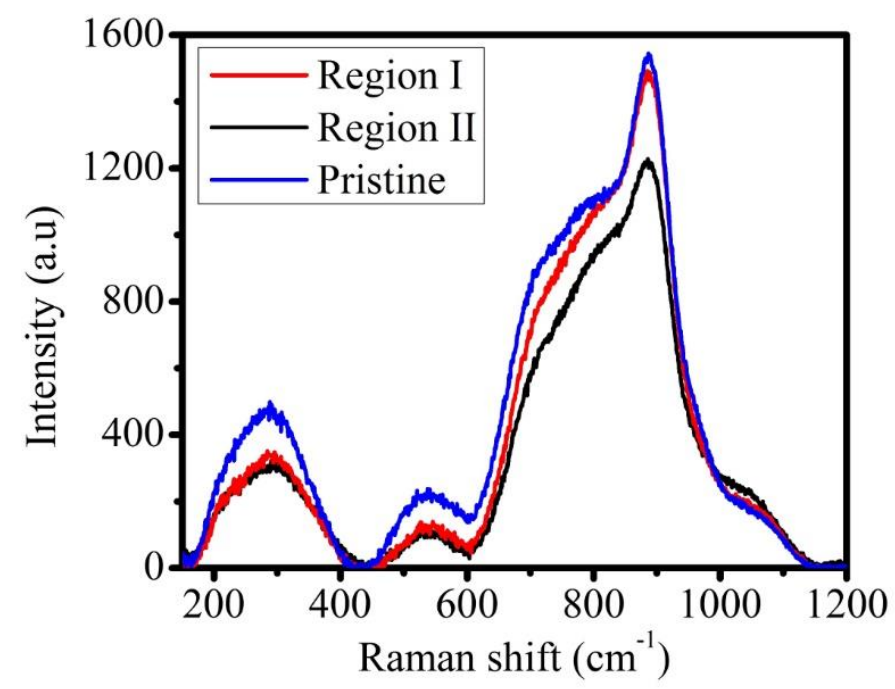

Fig. 5. $\mu$ Raman spectra recorded at the different regions of the structure in Fig. 4a, showing the change in the intensity of the different bands.

\subsection{Type II optical waveguides}

Similar to the strategy employed for the laser writing of waveguides in crystals [18], we employed a type II geometry consisting of two closely separated laser modification lines to produce a stress induced waveguide, for better confinement of the optical mode. The lowest insertion losses were obtained with a power of $80 \mathrm{~mW}$, speed of $20 \mathrm{~mm} / \mathrm{s}$ and separation of $14 \mu \mathrm{m}$ (Fig. 6), yielding an IL of $9.2 \mathrm{~dB}$ (including coupling losses of $2.9 \mathrm{~dB}$ per facet and propagation loss of $0.7 \mathrm{~dB} / \mathrm{cm}$ ). The propagation losses are comparable to those reported in other type-II waveguides [56, 57]. The mode field diameter of the waveguide $9 \mu \mathrm{m} \times 15 \mu \mathrm{m}$, significantly smaller than mode size of the single line structure in Fig. $2 \mathrm{~b}$, having a mode size of $\sim 18 \mu \mathrm{m}$. Future work will explore more exotic configurations (for example, 4-line [16] or circular structures [56]) to gain more control over the mode size.

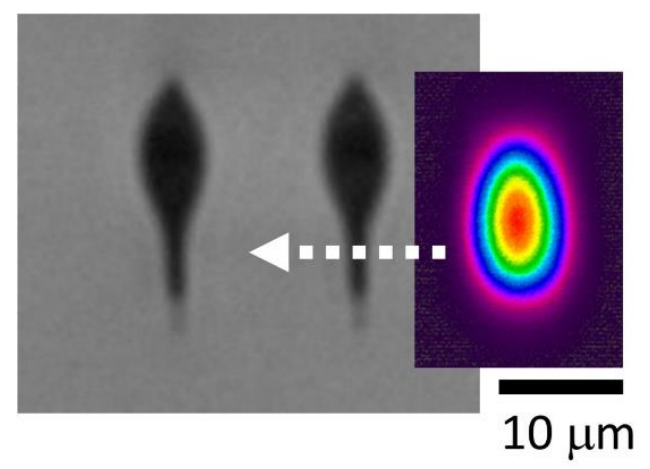

Fig. 6. Transmission optical microscope image and near-field intensity mode profiles (wavelength of $808 \mathrm{~nm}$ ) of the type II waveguide written with $P=80 \mathrm{~mW}, v=20 \mathrm{~mm} / \mathrm{s}$, and separation between lines of $14 \mu \mathrm{m}$. The scale bar is the same for the microscope image and mode profile.

\section{Conclusions}


Waveguides in Schott N-SF8 glass have been fabricated using a high repetition rate femtosecond laser. A decrease in the refractive index of the material has been observed as a consequence of the laser irradiation. EDX measurements show no significant changes in the composition inside the irradiated volume, therefore we have associated the decrease in the refractive index to an increase in the volume of the glass due to glass network modifications. From the Raman spectra, these network modifications are associated to the breakdown of the $\mathrm{Ti}$ and network modifiers rich regions, producing the release of the network modifiers and then increasing the non-bridging oxygens in the silica network and the disorder of the $\mathrm{Si}-\mathrm{O}-\mathrm{Si}$ angles. The increase in volume in the irradiated region creates compressive stress in the surroundings, forming guiding regions due to an increase in the refractive index. By laser writing two lines separated by $14 \mu \mathrm{m}$ we have been able to confine the optical mode and obtain propagation losses of $0.7 \mathrm{~dB} / \mathrm{cm}$.

\section{Acknowledgements}

This work has been supported by the FP7 DiamondFab CONCERT Japan project, DIAMANTE MIUR-SIR grant, and FemtoDiamante Cariplo ERC reinforcement grant. We thank Guglielmo Lanzani and Luigino Criante for the use of the FemtoFab facility at CNST - IIT Milano for the laser fabrication experiments. This research was partially supported by the Singapore Ministry of Education (MOE2011-T3-1-005).

\section{References}

[1] H. Zhang, S. Ho, S. M. Eaton, J. Li, P. R. Herman, Opt. Express, 16 (2008), pp. 14015-14023.

[2] S.M. Eaton, M.L. Ng, R. Osellame, P.R. Herman, Journal of Non-Crystalline Solids, 357 (2011), pp. 2387-2391.

[3] T.T. Fernandez, S.M. Eaton, G. Della Valle, R.M. Vazquez, M. Irannejad, G. Jose, A. Jha, G. Cerullo, R. Osellame, P. Laporta, Opt. Express, 18 (2010), pp. 20289-20297.

[4] R. Osellame, V. Maselli, R.M. Vazquez, R. Ramponi, G. Cerullo, Applied physics letters, 90 (2007), p. 231118.

[5] A. Borowiec, H. Haugen, Applied Physics Letters, 82 (2003), pp. 4462-4464.

[6] R.R. Gattass, E. Mazur, Nature photonics, 2 (2008), pp. 219-225.

[7] K.M. Davis, K. Miura, N. Sugimoto, K. Hirao, Optics letters, 21 (1996), pp. 1729-1731.

[8] J.W. Chan, T.R. Huser, S. Risbud, D. Krol, Applied Physics A, 76 (2003), pp. 367-372.

[9] K. Hirao, K. Miura, Journal of non-crystalline solids, 239 (1998), pp. 91-95.

[10] P. Dekker, M. Ams, G. Marshall, D. Little, M. Withford, Opt. Express, 18 (2010), pp. 3274-3283.

[11] T.T. Fernandez, P. Haro-González, B. Sotillo, M. Hernandez, D. Jaque, P. Fernandez, C. Domingo, J. Siegel, J. Solis, Optics letters, 38 (2013), pp. 5248-5251.

[12] T.T. Fernandez, M. Hernandez, B. Sotillo, S.M. Eaton, G. Jose, R. Osellame, A. Jha, P. Fernandez, J. Solis, Opt. Express, 22 (2014), pp. 15298-15304.

[13] M. Shimizu, M. Sakakura, S. Kanehira, M. Nishi, Y. Shimotsuma, K. Hirao, K. Miura, Optics letters, 36 (2011), pp. 2161-2163.

[14] J.W. Chan, T.R. Huser, S.H. Risbud, J.S. Hayden, D.M. Krol, Applied physics letters, 82 (2003), pp. 2371-2373.

[15] L.B. Fletcher, J.J. Witcher, W.B. Reichman, A. Arai, J. Bovatsek, D.M. Krol, Journal of Applied Physics, 106 (2009), p. 083107.

[16] B. Sotillo, V. Bharadwaj, J. Hadden, M. Sakakura, A. Chiappini, T.T. Fernandez, S. Longhi, O. Jedrkiewicz, Y. Shimotsuma, L. Criante, R. Osellame, G. Galzerano, M. Ferrari, K. Miura, R. Ramponi, P.E. Barclay, S. M. Eaton, Scientific reports, 6 (2016).

[17] J. Burghoff, S. Nolte, A. Tünnermann, Applied Physics A, 89 (2007), pp. 127-132.

[18] F. Chen, J. Aldana, Laser \& Photonics Reviews, 8 (2014), pp. 251-275.

[19] S. Karlsson, L.G. Bäck, P. Kidkhunthod, K. Lundstedt, L. Wondraczek, Opt. Mater. Express, 6 (2016), pp. 11981216.

[20] K. Inoue, S. Sakida, T. Nanba, Y. Miura, Materials Science And Technology: Materials and Systems, 1 (2006), pp. 583-593.

[21] G. Scannell, S. Barra, L. Huang, Journal of Non-Crystalline Solids, 448 (2016), pp. 52-61.

[22] E. Fargin, A. Berthereau, T. Cardinal, G. Le Flem, L. Ducasse, L. Canioni, P. Segonds, L. Sarger, A. Ducasse, Journal of non-crystalline solids, 203 (1996), pp. 96-101. 
Published in Optical Materials 72, pp. 626-631 (2017).

https://authors.elsevier.com/a/1VMOu3IPalOGPb

[23] N. Shimoji, T. Hashimoto, H. Nasu, K. Kamiya, Journal of non-crystalline solids, 324 (2003), pp. 50-57.

[24] Q. Xiang, Y. Zhou, Y.L. Lam, Y.C. Chan, C.H. Kam, B.S. Ooi, H.X. Zhang, S. Buddhudu, Materials Research Bulletin, 35 (2000), pp. 1571-1578.

[25] D.M. Boye, A.J. Silversmith, J. Nolen, L. Rumney, D. Shaye, B.C. Smith, K.S. Brewer, Journal of Luminescence, 94-95 (2001), pp. 279-282.

[26] R.D. Maurer, Proceedings of the IEEE, 61 (1973), pp. 452-462.

[27] M. Abdel-Baki, F. El-Diasty, International Journal of Optics and Applications, 3 (2013), pp. 125-137.

[28] D. Smith, C. Black, C. Homes, E. Shiles, Physica Status Solidi C, 4 (2007), pp. 838-842.

[29] R.R. VanBrocklin, W.D. Navan, M.J. Edwards, Corning: supplier of multiple optical materials for telescope projects, SPIE Astronomical Telescopes+ Instrumentation, International Society for Optics and Photonics2006, pp. 62730I-62730I-62738.

[30] B. Gholipour, P. Bastock, C. Craig, K. Khan, D. Hewak, C. Soci, Advanced Optical Materials, 3 (2015), pp. 635 641.

[31] http://www.schott.com/d/advanced optics/5cd5927c-7fd9-460c-92b6-e53f32dec017/N-

SF8 SDS EN V5 201505.pdf?tenant=ao-cert.

[32] http://www.sydor.com/wp-content/uploads/SCHOTT-N-SF8-Optical-Glass.pdf.

[33] C.B. Schaffer, A. Brodeur, E. Mazur, Measurement Science and Technology, 12 (2001), p. 1784.

[34] C. Hnatovsky, R. Taylor, E. Simova, V. Bhardwaj, D. Rayner, P. Corkum, Journal of applied physics, 98 (2005), p. 013517.

[35] S.M. Eaton, H. Zhang, M.L. Ng, J. Li, W.-J. Chen, S. Ho, P.R. Herman, Opt. Express, 16 (2008), pp. 9443-9458.

[36] S.M. Eaton, H. Zhang, P.R. Herman, F. Yoshino, L. Shah, J. Bovatsek, A.Y. Arai, Opt. Express, 13 (2005), pp. 4708-4716.

[37] S. Nolte, M. Will, J. Burghoff, A. Tünnermann, Journal of Modern Optics, 51 (2004), pp. 2533-2542.

[38] A. Arriola, S. Gross, N. Jovanovic, N. Charles, P.G. Tuthill, S.M. Olaizola, A. Fuerbach, M.J. Withford, Opt. Express, 21 (2013), pp. 2978-2986.

[39] S.M. Eaton, C. Merchant, R. Iyer, A. Zilkie, A. Helmy, J. Aitchison, P. Herman, D. Kraemer, R. Miller, C. Hnatovsky, Applied Physics Letters, 92 (2008), p. 081105.

[40] F. Farges, G.E. Brown, A. Navrotsky, H. Gan, J.J. Rehr, Geochimica et Cosmochimica Acta, 60 (1996), pp. 30393053 .

[41] F. Farges, G.E. Brown, A. Navrotsky, H. Gan, J.R. Rehr, Geochimica et Cosmochimica Acta, 60 (1996), pp. 3055-3065.

[42] F. Farges, G.E. Brown, J.J. Rehr, Geochimica et Cosmochimica acta, 60 (1996), pp. 3023-3038.

[43] A.A. Osipov, G.G. Korinevskaya, L.M. Osipova, V.A. Muftakhov, Glass Physics and Chemistry, 38 (2012), pp.

357-360.

[44] G.S. Henderson, M. Fleet, The Canadian Mineralogist, 33 (1995), pp. 399-408.

[45] Q. Liu, R.A. Lange, Y. Ai, Geochimica et Cosmochimica Acta, 71 (2007), pp. 4314-4326.

[46] G. Henderson, X. Liu, M. Fleet, Physics and Chemistry of Minerals, 29 (2002), pp. 32-42.

[47] L. Cormier, P. Gaskell, G. Calas, A. Soper, Physical Review B, 58 (1998), p. 11322.

[48] Q. Liu, R.A. Lange, Geochimica et Cosmochimica Acta, 65 (2001), pp. 2379-2393.

[49] B. Reynard, S.L. Webb, Eur. J. Mineral, 10 (1998), pp. 49-58.

[50] P. McMillan, American Mineralogist, 69 (1984), pp. 622-644.

[51] Z. Wang, Q. Shu, K. Chou, ISIJ international, 51 (2011), pp. 1021-1027.

[52] T. Fernandez, G. Jose, S. Mathew, P. Rejikumar, N. Unnikrishnan, Journal of sol-gel science and technology, 41 (2007), pp. 163-168.

[53] A. Chiasera, C. Tosello, E. Moser, M. Montagna, R. Belli, R. Gonçalves, G. Righini, S. Pelli, A. Chiappini, L. Zampedri, Journal of non-crystalline solids, 322 (2003), pp. 289-294.

[54] Y. Yonesaki, K. Miura, R. Araki, K. Fujita, K. Hirao, Journal of non-crystalline solids, 351 (2005), pp. 885-892.

[55] M. Montagna, E. Moser, F. Visintain, M. Ferrari, L. Zampedri, A. Martucci, M. Guglielmi, M. Ivanda, Journal of sol-gel science and technology, 26 (2003), pp. 241-244.

[56] M.-M. Dong, C.-W. Wang, Z.-X. Wu, Y. Zhang, H.-H. Pan, Q.-Z. Zhao, Opt. Express, 21 (2013), pp. 1552215529.

[57] A.H. Nejadmalayeri, P.R. Herman, Opt. Express, 15 (2007), pp. 10842-10854. 